\title{
El Mínimum Vital en sus relaciones con el derecho (El vitalismo desde una perspectiva teórico-práctica)
}

Otto Mejía Brugos ${ }^{1}$

Recibido en septiembre de 2015, aceptado en noviembre de 2015.

\begin{abstract}
Resumen
En este artículo se hace un análisis del Mínimum Vital desde un punto de vista poco tratado hasta el momento, el cual es plantear sus relaciones con el derecho. Trata de demostrar que dicha teoría no es utópica o ingenua como muchas veces se le ha calificado por parte de sus detractores, sino más bien el resultado de una ética que paulatinamente debe irse incorporando en la sociedad a través de leyes e instituciones concretas. Hace notar que el fin último del vitalismo es producir un mayor grado de bienestar social para lo cual debe de auxiliarse de una maquinaria formal, que es el derecho.
\end{abstract}

Palabras claves:

Mínimum Vital, derecho, ley, justicia social, capitalismo.

\begin{abstract}
:
This article makes an analysis of Mínimum Vital theory since a point of view little-known until now, which is to bring up its relations with the laws; try to prove that this doctrine is not utopic or ingenous as so many times has been qualified by its opponents, but it's a result of an etic which gradually must be incorporate into the society through the concrete laws and institutions. It makes to notice that the principal vitalism's objective is to produce a greater level of social well-being consequently it must to help of a formal machine that is the system legal.
\end{abstract}

\section{Keywords:}

Mínimum Vital, right, law, social justice, capitalism.

1. Abogado y Notario (UES). Doctor en Filosofía Iberoamericana por la Universidad Centroamericana José Simeón Cañas (UCA). Email: ottogmb7@hotmail.com 
Es claro que la doctrina formulada por el gran pensador salvadoreño Alberto Masferrer siempre ha sido objeto de un gran número de análisis desde diferentes ópticas: la histórica, la sociológica, la política y la eidética. Sin embargo, a pesar de que es evidente que, en esencia, constituye la reivindicación a los derechos humanos fundamentales de todo conglomerado social, no existe un estudio de vena jurídico-filosófica donde se fundamente que dicho cuerpo de ideas puede constituir una fuente de inspiración para el derecho positivo, tanto a nivel nacional como internacional. Masferrer siempre adversó a los eruditos inconsecuentes con la realidad, siempre quiso que sus propuestas se materializaran en leyes efectivas. Es por eso que se vuelve necesario realizar una visión más pragmática del vitalismo con el objeto de alcanzar la tan anhelada justicia social, que es la base para la construcción de una auténtica democracia real.

Las siguientes reflexiones tienen su eje transversal en la conferencia titulada El vitalismo en sus relaciones con el derecho dictada por Mario Vargas Morán en la Confederación de Obreros de El Salvador el 3 de octubre de 1929, la cual se realizó en función de dar a conocer aún más entre el público, el Mínimum Vital de Masferrer. Además, se hace uso de otros artículos vitalistas dispersos publicados durante esa misma época en el periódico Patria, los cuales guardan una íntima relación con el tema a tratar. En ese sentido, se debe comenzar por decir que para Vargas Morán, el Mínimum Vital era una doctrina que realizaba una nueva interpretación de la justicia en un sentido social. ${ }^{2}$ Así que lo primero que debemos plantearnos es ¿Qué debemos entender por justicia? y ¿Qué debemos entender por justicia social?

El tema de la justicia siempre inquietó a los grandes filósofos de la Antigüedad. Como es bien sabido, Aristóteles en La ética a Nicómaco proporcionó su concepto de "justicia distributiva” el cual es "dar a cada uno lo que le corresponde; es decir, en proporción a la contribución a la sociedad, sus necesidades y sus méritos personales", pero al mismo tiempo habló de la "justicia conmutativa”, la cual consiste en dar a todos por igual. ${ }^{3}$

Platón en La República también tocó con cierta profundidad el tema de la justicia, lo cual puede comprobarse a través de los diálogos entre Sócrates, Céfalo y Polemarco, los cuales giran en torno a la discusión de cómo debe entenderse dicho término desde distintos ángulos: como una retribución por una falta o delito, como la correcta distribución de las riquezas, como la actitud de decir siempre la verdad, como el hecho de hacer el bien y abstenerse de hacer el mal, etc. Pero lo importante aquí es que todos tenían diferentes visiones de lo que debía entenderse por justicia. ${ }^{4}$

2. Mario Vargas Morán, "El vitalismo y sus relaciones con el derecho I", Patria, viernes 8 de noviembre de 1929 , No. 460 , pág. 3 , año II.

3. F. Javier Murillo Torrecilla y otro, "Hacia un concepto de justicia social", REICE, Revista Iberoamericana sobre calidad, eficacia y cambio en educación, Vol. 9, No. 4, 2011, págs. 8 y 9.

4. Platón, La República, Editorial Gradifco, Buenos Aires, Argentina, 2007, págs. 20, 21, 22, 23, 24, 
Para Beatrice de Carrillo, al hablar de justicia indefectiblemente se tiene que hacer relación al derecho y la ley. Para la jurista, los derechos humanos son, según sus mismas palabras: "la expresión universal de justicia en la historia" y define "justicia" como una "categoría racional del pensamiento" cuyo objetivo es producir un equilibrio u orden universal. Para la jurisconsulta, el derecho es una encarnación de la justicia y la ley etimológicamente hablando sugeriría un "pacto entre partes", es decir, un acuerdo en una relación social. Desde su perspectiva, Sócrates, Platón y Aristóteles concibieron la justicia como una virtud integral, entendiendo esto como una aglutinación de todas las demás virtudes o, en otras palabras, la justicia sería el valor supremo encaminado a la praxis. ${ }^{5}$

John Rawls en su Teoría de la justicia (1971) propone un concepto multidisciplinario de justicia en el cual pretende superar las conceptualizaciones utilitaristas e intuicionistas de su época. Al igual que Masferrer intenta establecer aquellos principios morales que deben orientar a una sociedad bien ordenada en un marco de cooperación equilibrada. Estos principios serían elegidos a través de un contrato hipotético de modo que todos los participantes se adhirieran a él por ser -a consideración de todos-, los más justos. Es decir, Rawls se decantaría por una línea del derecho denominada "iusnaturalista", la cual explicaremos más adelante a través de Kelsen. ${ }^{6}$

La idea de justicia en Rawls tiene que ver con la distribución de las cargas y beneficios en la cooperación social. Esto quiere decir igualdad de posibilidades como eje central de la justicia distributiva dentro de un sistema democrático. Esta concepción de justicia requiere que los recursos o bienes primarios sean distribuidos de manera igualitaria dentro de la sociedad y con ello se refiere a bienes naturales y sociales. En este sentido, las instituciones velarían de manera especial porque esos bienes llegarán a aquellas personas que naturalmente han sido menos favorecidas. ${ }^{7}$ Como es obvio advertir, la mayoría de autores concuerdan en ciertos criterios para establecer sí una sociedad es justa o no, los cuales son, según Elster, los que estarían basados en el sistema de libertades, obligaciones y distribución de ingresos. ${ }^{8}$

Pero este ensayo, no pretende ser un estudio sistemático y exhaustivo de lo que cada filósofo o escuela de pensamiento ha entendido por justicia, sino más bien, pretende demostrar que el tema de la justicia siempre ha preocupado a los grandes pensadores en las distintas épocas de la historia, ya que uno de sus

$25,26,27,28,29,30,31,32,33,34$ y 35 .

5. Beatrice Alamanni de Carrillo, Justicia, derecho y ley, $1^{\text {a }}$ Ed., Editorial UCA, San Salvador, El Salvador, 2009, págs. 9 y 10.

6. Yesid Echeverry Enciso y otro, "El concepto de justicia en John Rawls", Revista Científica Guillermo de Ockham, volumen 4, No. 2, julio-diciembre 2006, Colombia, págs. 28 y 29.

7. Ibídem, págs. 31, 32, 33 y 34 .

8. José Francisco Caballero, "La teoría de la justicia de John Rawls", Voces y contextos, No. 2, año I, 2006, pág. 1. 
ideales siempre ha sido tratar de organizar de la mejor manera a las sociedades en las que les tocó vivir. Según Javier Murillo Torrecilla y Reyes Hernández Castilla, el primero en utilizar el término "justicia social" fue el sacerdote Jesuita italiano Luigi Taparelli d'Azeglio en su obra Ensayo teórico sobre el derecho natural apoyado en los hechos de 1843, al establecer que la "justicia social" consiste en igualar de hecho a todos los hombres en lo tocante al derecho. Estos académicos creían que el término encontraría profundidad a raíz de las desigualdades sociales y económicas provocadas por el sistema capitalista. ${ }^{9}$

La expresión "Justicia Social” se generalizó en las últimas fases de la Primera Revolución Industrial. La idea era aplicarla a los conflictos obreros que se extendieron a raíz del establecimiento del maquinismo y la sociedad industrial. Bajo este sistema económico irá evolucionando y no será ajena a los mecanismos de desarrollo de la economía. Su puesta en práctica se basó en el crecimiento económico generado por la sociedad industrial y, entre ésta, de modo especial, por la economía de mercado. Nació bajo el signo de la protección, objetivada en la clase trabajadora explotada, para más tarde aspirar a corregir todos los defectos provocados por el sistema capitalista. De manera que la Justicia Social creció al amparo de unas premisas motivadas por la injusticia económica.

Es en este contexto de exclusión social en el cual, precisamente, Masferrer escribió su Mínimum Vital. El maestro vio en algunos sencillos postulados el remedio 0 , al menos, un calmante a todos los males derivados del sistema capitalista, que, en ese momento se encontraba pasando por una de sus etapas más difíciles desde sus orígenes: la depresión económica mundial de 1929. Esta crisis, incluso, hacía más apremiante la búsqueda de una solución. Una de las formas que encontró Masferrer para crear una sociedad más justa, fue publicar artículos que causaran un mayor acercamiento y una mayor armonía entre las clases dominantes y las clases explotadas, sobre todo en cuanto a ciertas reivindicaciones que las primeras tenían que realizar en favor de los segundas.

Uno de estos artículos llevó por título "Los diez mandamientos de la justicia social" de los cuales los primeros cinco podrían sintetizarse así: 1) "Yo soy el Señor tu Dios, pero debes recordar también que soy el Dios de toda la Tierra, (...) son todos mis hijos amados". Este mandamiento quiere decir que todos los seres humanos independientemente de su raza o condición social son hermanos y por tanto, no debe prevalecer el egoísmo entre ellos; 2) "No midas la grandeza de una ciudad por su población y sus bancos solamente, sino también por su bajo nivel de mortalidad infantil, (...) sus bibliotecas, sus escuelas y hospitales..." Este mandamiento quiere revelar que la importancia 
de un país no sólo debe medirse por sus finanzas y prosperidad económica sino también por la implementación de ciertas políticas sociales; 3) "Recuerda que ninguna civilización puede ser superior al nivel de respeto y sus ideales por la mujer". Este mandamiento quiere expresar que en toda sociedad la mujer debe tener iguales derechos y oportunidades que el hombre y que debe existir una educación que garantice su respeto; 4) "Recuerda tus propios pecados y no construyas prisioneros de venganza y castigo, pero haz de tus tribunales clínicas para el alma y de tus cárceles hospitales para las enfermedades del alma". Este mandamiento sostiene que los seres humanos tienen que perdonarse los unos a los otros y no guardar resentimientos que los impulsen a tomar venganza en contra de su prójimo; 5) "Recuerda que el verdadero producto de la industria no son mercancías ni dividendos, sino la clase de hombres y mujeres cuya vida es plasmada por aquella industria". Este mandamiento pretende concientizar de que el capital, el sistema de producción y la plusvalía nunca deben prevalecer por sobre la dignidad e integridad del ser humano que produce esa riqueza y que todo hombre y mujer tienen derecho a no ser explotados en su trabajo. ${ }^{10}$

Los otros cinco mandamientos podrían resumirse así: 6) "Avanza de la democracia política hacia la democracia industrial, recordando que ningún hombre es bastante bueno ni bastante sano para gobernar a otro hombre sin su consentimiento, y que además de un salario suficiente para vivir, todo hombre desea una razonable participación en la determinación de las condiciones bajo las cuales trabaja". En este mandamiento se pone de manifiesto lo que se señalaba al principio del artículo: para que exista una democracia verdadera debe existir primero justicia social, los gobernantes deben ser electos por el pueblo, pero además estos gobernantes deben velar por los intereses de los trabajadores, es decir, la democracia política y la económica deben ir de la mano; todo trabajador tiene derecho a un salario justo y a obtener una participación en las ganancia de su patrono; 7) "Proscribe la guerra y no hagas gestos amenazadores con grandes armas (...) contra tu vecino". Este mandamiento invita a invertir el dinero del Estado en las necesidades primarias del pueblo y evitar las guerras contraproducentes; 8) "Honra al hombre sólo por el carácter y los servicios y no deshonres a ninguno por razón de raza, color o anteriores condiciones de servidumbre". Este mandamiento indica que todo trabajo dignifica y que no es correcto realizar discriminaciones de ningún tipo, ya que el hombre por el sólo hecho de serlo está dotado de una dignidad humana; 9) "No levantes falso testimonio contra tu vecino...”. Este mandamiento está en claro parafraseo de la biblia y no necesita mayor explicación y 10) "Recuerda que cuando tus propios antepasados eran salvajes y bárbaros otros hombres los ayudaron a civilizarse...". Se Interpreta este mandamiento como aquella solidaridad que debe existir entre los hombres y pueblos avanzados y los hombres y pueblos rezagados. Los primeros deben ayudar a progresar a los segundos. ${ }^{11}$

10. “Los diez mandamientos de la justicia social”, Patria, viernes 7 de junio de 1929, No. pág. 3, año I. 11. Ídem. 
En base a lo anterior, queda de manifiesto que Mínimum Vital pretendía introducir una especie de moralidad laica que impregnara a toda la estructura social. Es en esta misma dirección que tuvo lugar la conferencia de Vargas Moran, en la que estableció que desde hacía tiempo, los sociólogos en base a las ideas del médico y biólogo Claudio Bernard, habían concebido a las sociedades como una suerte de organismos vivientes, es decir, como entes compuestos de muchas partes que colaboraban entre sí, para el sostenimiento de todo el sistema. ${ }^{12}$

Para Vargas Morán, estos teóricos veían a la sociedad civil como un ser vivo cuya alma colectiva era distinta a la de sus asociados; es decir, dentro de este esquema organicista los individuos jugaban un papel similar al que jugaban las células y los órganos dentro de un mismo organismo biológico vivo. Las clases dirigentes constituirían el cerebro, el comercio, el sistema circulatorio y la clase trabajadora, la energía que movía el organismo, o, en otras palabras, el músculo. Es en este proceso justamente donde el sistema económico no debía servir como enervante de todo el organismo. ${ }^{13}$

Esto obviamente es el resultado de una concepción filosófica positivista de la sociedad, la cual estaba en clara decadencia en ese momento, como lo reconocía el mismo Vargas Morán. ${ }^{14}$ Uno de los grandes errores del positivismo, es querer explicar artificiosamente la organización, dinámica y progreso de las sociedades desde leyes, categorías y principios que vienen de las ciencias naturales y que no necesariamente son compatibles o aplicables a la realidad social. La sociología surgió pues en un afán exacerbado del positivismo por encontrar una ciencia humanista que explicara de manera rígida, exacta y objetiva, como sí se tratare de un problema matemático, los procesos sociales, tal como lo explica Augusto Comte:

Así se llega gradualmente a descubrir la invariable jerarquía, a la vez histórica y dogmática, de igual modo científica y lógica, de las seis ciencias fundamentales: la matemática, la astronomía, la física, la química, la biología y la sociología. La primera de ellas constituye necesariamente el punto de partida exclusivo, y la última, el único fin esencial de toda filosofía positiva, considerada desde ahora como algo que forma, por su naturaleza, un sistema verdaderamente indivisible, donde toda descomposición es radicalmente artificial, sin ser, por otra parte, de ningún modo arbitraria, y que se refiere finalmente a la Humanidad, única concepción plenamente universal. ${ }^{15}$

12. Mario Vargas Morán, "El vitalismo y sus relaciones con el derecho I", Patria, viernes 8 de noviembre de 1929, No. 460, pág. 3, año Il.

13. Ídem.

14. Ídem.

15. Augusto Comte, Discurso sobre el espíritu positivo, libro digitalizado por Dot-com. Disponible en http://www.libro.dot.com, págs. 47 y 48. 
No obstante lo erróneo de la teoría, Vargas Morán creía que era útil para explicar las concepciones vitalistas. En primer lugar, creía que el sistema social, entendido como organismo, efectivamente estaba enfermo porque uno de sus órganos no estaba funcionando de manera eficiente, ya que otro lo mantenía totalmente extenuado por el sobreesfuerzo. En este punto y para una mejor comprensión quizás habría que utilizar la teoría de la división de clases de Marx, con la aclaración que, en el sistema organicista, los distintos órganos nunca debían contraponerse sino actuar en armonía, pero, en el ámbito social, resultaba que existía un gran parásito llamado "clase pudiente" que absorbía la vida y los nutrientes de los otros órganos notablemente más débiles. Esta anomalía producía de manera inevitable el dolor, el malestar y el desequilibrio del sistema. ${ }^{16}$

El Mínimum Vital sostiene que en ese, como en cualquier otro organismo, el bienestar general se mide en relación directa con el bienestar de todas y cada una de las células elementales y en relación inversa con el desarrollo de las formaciones parasitarias. El cáncer nunca ha sido recomendado por la higiene. El parasitismo tampoco puede ser recomendado como remedio social. Y predica, en resumen, que si arreglamos ese organismo de manera que todas las células puedan funcionar y desarrollarse normalmente; si a todas ellas les proporcionamos los elementos estrictamente indispensables siquiera, el bienestar en conjunto será un hecho.

Lo que Vargas Morán trataba de explicar era -aunque no sea un hecho tan manifiesto-, que todos los hombres están en intima interdependencia; explica que en la época moderna ni las personas ni las naciones podían permanecer aisladas unas de otras. Fenómenos como la caída de la bolsa de valores en Wall Street o las guerras mundiales demostrarían esta hipótesis, ya que todas las naciones en el mundo, en menor o en mayor medida, y aunque fuera de forma imperceptible, experimentaban sus efectos. El ignorar tal situación era lo que, según este intelectual, traía en una sociedad concreta la lucha de clases, la cual tenía como motor el egoísmo del capitalista y del especulador, egoísmo que permanecía en él como parte de su naturaleza animal. ${ }^{17}$

Para que este instinto no prevaleciera por siempre y para que el más débil no desapareciera ante el poderío del más fuerte, es que el animal racional creó las leyes y el derecho o en una palabra la civilización, en la cual todos los individuos debían armonizar sus intereses con los de sus prójimos aunque estos claramente estuvieran en contraposición, es decir, todos los hombres debían adaptarse a vivir una vida en común y evolucionar de su faceta individual a su

16. Mario Vargas Morán, "El vitalismo y sus relaciones con el derecho I", Patria, viernes 8 de noviembre de 1929, No. 460, pág. 3, año II.

17. Ídem. 
faceta social. En su faceta animal, el hombre despreciaba la vida del otro, en su faceta social, el hombre protegía la vida la vida del otro y esa era la íntima relación que existía entre el Mínimum Vital y la ciencia del derecho. ${ }^{18}$

En este sentido, el contrato social de Rousseau establece que un colectivo se funda en el principio de elección libre en cuanto que cada individuo decide establecer un vínculo con el conglomerado, o sea, existe una voluntad de convivir con sentido social y de establecer relaciones civiles entre los asociados. La teoría se fundamenta en que todo hombre tiene una autonomía o libertad como estado legítimo y original. Habría que aclarar, sin embargo, que el contrato social no es un acto puntual que origina la existencia de un pueblo en un momento histórico determinado, ni un hecho empírico constatable, sino más bien una noción racional que Rousseau utiliza para explicar cómo los distintos individuos aceptan una forma de gobierno. El contrato es hipotético, es tácito, no está plasmado en ningún documento, pero sí habría que especificar que el término hace referencia al momento político en que un pueblo se autoconstituye como sujeto colectivo autónomo. ${ }^{19}$

Rousseau percibe el contrato social como "una suma de fuerzas". El requisito indispensable para que tenga lugar dicha adhesión de energías es vencer la resistencia de cada voluntad particular. En el contrato social ideado por Rousseau, la voluntad individual y la voluntad colectiva coinciden; es decir, el contrato social es un cuerpo moral que da protección a sus miembros preservando su libertad, lo cual quiere decir que no coacciona a nadie para que integre el conglomerado social, sino que cada individuo aporta libremente su cuota de voluntad individual para el establecimiento de un conglomerado organizado en donde se empiezan a establecer relaciones de derecho. En este escenario la voluntad particular nunca podrá prevalecer sobre la voluntad general. ${ }^{20}$

Cada uno de nosotros pone en común su persona y todo su poder bajo la suprema dirección de la voluntad general, y nosotros recibimos además a cada miembro como parte indivisible del todo. Este acto produce inmediatamente, en vez de la persona particular de cada contratante, un cuerpo moral y colectivo, compuesto de tantos miembros como votos tiene la asamblea, el cual recibe de este mismo acto su unidad, su yo común, su vida y su voluntad. ${ }^{21}$

El contrato social trata de describir conceptualmente cómo las sociedades humanas se han organizado, no de forma accidental, sino como actos políticos convencionales. Al darse estos acuerdos de voluntad nace el Estado el cual está

18. Ídem.

19. Jean-Jacques Rousseau, El contrato social, Editorial Biblioteca Nueva, Madrid, España, 2003, págs. 19,20 y 21.

20. Ibídem, págs. 22 y 23.

21. Ibídem, págs. 23 y 24. 
regido por leyes, independientemente de la administración que lo conduzca; es decir, el contractualismo teórico sostiene que allende del intendente político que dirija el Estado éste siempre estará sometido al interés público y las leyes serían las condiciones mínimas para la existencia y armonización de la asociación civil. Las leyes serían como una especie de mojones de esa asociación civil en cuanto a que la voluntad particular siempre deberá estar en conformidad con la voluntad general expresada en las leyes. ${ }^{22}$

En esa dirección, el Mínimum Vital intenta mediante la constitución de un sistema legal justo que un "órgano" o "clase social" en concreto no se aproveche del esfuerzo ajeno. Establece que en una sociedad concreta no se debe de tolerar la pereza de una minoría privilegiada en detrimento de una mayoría depauperada. El lema del capitalista es obtener el máximo de ganancias con el mínimo de esfuerzo y en muchos casos, sin ninguno, simplemente se apropia de la renta de los demás por ser el mero dueño de los medios de producción o en base a la mera actividad especulativa del sistema financiero. ${ }^{23}$

Vargas Morán, recuerda que la sociedad debe estar constituida a modo de crear un orden de cosas justo y no a conceder protección a ciertas castas privilegiadas como fue en tiempos del feudalismo de la Europa Occidental en donde los nobles terratenientes tenían el poder económico y político. En estas grandes propiedades rurales se producían los alimentos básicos, por lo que los ciudadanos sin tierra buscaban la protección de un señor feudal, quien prácticamente los esclavizaba. Vargas Morán, describe a estos feudos como comarcas semi-bárbaras protegidas por muros similares a los de un castillo, en donde sus habitantes eran encerrados y aislados viviendo en la incomodidad, la opresión y el miedo. Para él, es por eso que no era una casualidad que a la Edad Media se le conociera con el nombre de la "Edad del Miedo". En este sistema, incluso, estuvo vigente el derecho de "prima nocte" a favor del Señor de las tierras. ${ }^{24}$

Vargas Morán explica que en la época feudal, los nobles gozaban de muchos fueros y privilegios mientras que al plebeyo se le torturaba, encerraba, privaba de libertad, incautaba en sus bienes e incluso ejecutaba, por el simple argumento de hacerse bajo las órdenes y autoridad del Señor Feudal, quien era quien impartía justicia. Estas desigualdades fueron provocando el odio entre la comunidad, de generación en generación, hasta que se proclamó el derecho de "igualdad" como derecho político, que es uno de los pilares fundamentales de la Revolución Francesa. ${ }^{25}$

22. Ibídem, págs. 31, 57 y 91 .

23. Mario Vargas Morán, "El vitalismo y sus relaciones con el derecho I", Patria, viernes 8 de noviembre de 1929, No. 460, pág. 6, año II.

24. Mario Vargas Moran, "El Mínimum Vital y sus relaciones con el derecho II", Patria, domingo 10 de noviembre de 1929, No. 462, pág. 3, año II. El Feudalismo tuvo lugar entre los siglos IX-XII 25. Mario Vargas Morán, “El liberalismo y la democracia II”, Patria, viernes 21 de febrero de 1930, No.548, pág. 3, año II. 
Vargas Morán describió a la sociedad feudal como una de las más crueles y degradantes de la historia. En la época moderna, según él, este sistema había sido sustituido por otro que, aunque con muchas más sutilezas, había continuado la esclavitud y que el pensador que mejor lo había estudiado hasta ese momento era Karl Marx en su famoso libro El Capital. ${ }^{26}$ Efectivamente, el objetivo de dicha obra consiste en analizar la injusticia que produce el modelo liberal económico de la sociedad burguesa. Marx analiza pormenorizadamente cómo el capitalismo existe en función de producir mercancías, mercancías que no son creadas precisamente con el fin de satisfacer las necesidades básicas de todo ser humano que, es a lo que Marx llama -valor de uso- sino que con el afán de producir plusvalía. En este contexto, el trabajador es explotado en la búsqueda continua del capitalismo por lograr una mayor mecanización de la producción en la fiera batalla entre capitalistas por prevalecer en el mercado. En este sentido habría que decir que existe cierta aproximación entre el marxismo y el Mínimum Vital cuando Masferrer establece:

La máquina, endiosada, se está volviendo en la sociedad actual el diente y la garra de la fiera. Las vidas de los hombres, hasta de los niños, le son sacrificadas, ni más ni menos que lo fueran en los brazos candentes de Moloch. Que vuele el automóvil, aunque todos los días haya un niño o un anciano apachurrado; que la fábrica arroje a millones los productos, aunque los obreros sean despedidos sin aviso, sin indemnización, sin cuidado ninguno de lo que les espera, que la Singer se agite día y noche abaratando las prendas de vestir, mientras que a la par abarata la tuberculosis; que las mujeres y los niños se agoten en las hilaturas, y perezcan antes de tiempo, con tal que se abarate el producto. ${ }^{27}$

Ahora bien, habría que señalar enfáticamente que Vargas Morán no estaba de acuerdo con el gran metarrelato -casi mítico- sobre que ha existido una especie de conspiración mundial en la cual se juntaron todos los capitalistas y acordaron un plan siniestro para explotar al pobre. Él considera que ésta es una idea ingenua que se utiliza, a lo sumo, para conmover a las masas, pero que no está de conformidad con la realidad. Para él, nadie planeó malévolamente el feudalismo o el capitalismo sino que simplemente han sido fases o etapas en la búsqueda de una mejor adaptación entre la individualidad y la colectividad y que, por tanto, no habría que tomar la teoría marxista de forma dogmática: ${ }^{28}$

Ni Marx, ni nadie han podido precisar quién es el patrono por esencia y quién trabajador, porque en el entremezclamiento entre causas y

26 El Mínimum Vital y sus relaciones con el derecho II, Patria, domingo 10 de noviembre de 1929, No. 462 , pág. 3 , año II.

27. Alberto Masferrer, "Maquinas y hombres", Obras escogidas, tomo segundo, selección y prólogo de Matilde Elena López, $1^{\text {a }}$ Ed., editorial universitaria de El Salvador, 1971, pág. 228.

28. El Mínimum Vital y sus relaciones con el derecho II, Patria, domingo 10 de noviembre de 1929, No. 462 , pág. 3 , año II. 
efectos, todos son un poco trabajadores y un poco patronos. Y en cuanto al sistema, se cree en él, pero no se le define. Es algo dramático, oscuro y tenebroso, que no puede decirse en que consiste. Porque no es en la moneda porque la moneda existió desde tiempos inmemoriales. No es en la industria, porque ya había industria en la Edad Media. Nadie sabe en qué radica y cuál es su plan.

En este sentido, Vargas Morán establece que nadie tiene el monopolio de la verdad, que la verdad en sí misma no existe como no existe la bondad o la belleza que son sólo conceptos abstractos inventados por la inteligencia humana para describir el medio, por eso pensar que el capitalismo o el marxismo son la verdad única es absurdo. Son todos ensayos y es por eso que cree que los verdaderos pensadores siempre mantienen una postura crítica, siempre encuentran nuevas verdades. Para él, la verdadera actitud filosófica está en la búsqueda continua de la verdad y en esa línea de ideas, hay distintos tipos de verdad. Algunas que pueden ser probables, improbables, modestas, transitorias o útiles y otras que pueden llegar a ser, incluso, hasta contradictorias. Asimismo son los sistemas sociales: ${ }^{29}$

En sus relaciones interiores, la humanidad ha organizado sociedades para hacer factible la vida en común. Y hay que confesar que la sociedad humana constituye un rotundo fracaso. Cualquier especie animal o vegetal nos da ejemplos de perfecta adaptación. Cualquier comunidad de hormigas o de abejas nos enseña lo que una sociedad perfecta debe ser. Solo el hombre arrastra sus necesidades insatisfechas, por la oscuridad de su inadaptación.

Según Vargas Morán, la humanidad en su vida política, -como dijimos antes-, sólo ha pasado de ensayo en ensayo. Todos equivocados, pero establece siempre influenciado por las ideas positivistas que las ciencias sociales deben buscar un modelo que se ajuste más a las necesidades de los pueblos, así como la física trata de ser rigorista al estudiar los comportamientos de la materia. La ciencia idónea para encontrar este paradigma según él, era la economía política. ${ }^{30}$ En ese momento, sostenía la democracia era la base de la vida política en la mayoría de países del mundo, sistema que garantizaba perfectamente los derechos individuales, pero que tenía el enorme defecto de no reconocer los derechos colectivos, es decir, al estar supeditado a un sistema económico liberal, la democracia se volvía injusta, ya que no se protegía los derechos naturales como el agua, la luz y el aire. ${ }^{31}$

29. Mario Vargas Morán, “El vitalismo y su función social”, Patria, jueves 26 de septiembre de 1929, pág. 1, año II.

30. Mario Vargas Morán, "El liberalismo y la democracia I", Patria, jueves 20 de febrero de 1930, No. 547 , págs. 3 y 6 , año Il.

31. Mario Vargas Morán, "El liberalismo y la democracia III", Patria, sábado 22 de febrero de 1930, No. 549 , pág. 3 , año II. 
En fin, desde la óptica de Morán en las naciones democráticas había libertad política, pero al mismo tiempo un gran desorden social interno. No obstante esto, no debía buscarse soluciones que resultaran peores que la misma enfermedad. El comunismo, por ejemplo, desde su perspectiva solo era un sistema basado en el odio acumulado y "represalias ampliamente saboreadas con anterioridad" y por tanto, erróneo. Lo ideal, entonces, era buscar una cura progresiva bajo la noción de justicia social y el reconocimiento de las garantías colectivas. En ese sentido, el Mínimum Vital era una solución alterna a la hegemonía del socialismo marxista, la cual hacía un llamado a que todos los hombres comieran, trabajaran y vivieran en un medio social donde se distribuyeran mejor las riquezas sin caer por eso en la lucha de clases, es decir, además de la igualdad política, el Mínimum Vital buscaba la igualdad social que garantizara un trozo de pan, una pieza de tela y un techo: ${ }^{32}$

Es de justicia y debe ser ley. Ley que no despoje a nadie; que no expropie, que no cambie los viejos fundamentos hasta hoy insustituibles de la propiedad privada, pero sí que reconozca los derechos de la sociedad como persona moral independiente. Que limite los derechos de cada ciudadano, no tan solo por los derechos similares de los otros ciudadanos, sino por los derechos superiores de la colectividad.

En la anterior opinión hay un punto fundamental que no debe pasarse por alto y es por lo que el vitalismo ha sido objeto de abundantes críticas por parte de un gran número de pensadores marxistas y es que éste está concebido para operar dentro de un sistema capitalista en donde no necesariamente se debe de abolir la propiedad privada. La crítica a Masferrer en base a esto es que nunca pudo abandonar su estatus pequeño-burgués y que debido a esta condición nunca pudo entender las transformaciones de fondo que pretendía realizar el marxismo.

El socialismo que promueve el Mínimum Vital sería mucho menos radical que el que propone el marxismo y es por eso que dicha doctrina se suele calificar de "utópica", la cual iría más bien en la línea de un socialismo fabiano o un anarquismo socialista como el de Proudhon o Kropotkin, la cual, en una extraña mezcla, también se vería influenciada por la teosofía, corriente orientalista que el marxismo académico juzga como pseudofilosofía. El marxismo, por ejemplo, persigue la supresión de clases sociales mientras que el Mínimum Vital la disminución de la brecha entre ellas. Es por estas y otras razones que el pensamiento marxista observaría al vitalismo como una doctrina contradictoria, inocente y llena de buenas intenciones, pero sin la posibilidad real de llevarse a cabo. ${ }^{33}$

32. Ídem.

33. Regina Fuentes Oliva, "Crítica: el vitalismo de Masferrer", disponible en: www.caratula.net/ ediciones/44/critica-rfuentes.php 
Ahora bien, el vitalismo dentro del sistema capitalista tendría por objeto que el rico ya no existiera exclusivamente en función de sí mismo, sino en función de crear trabajo para elevar el nivel material, moral e intelectual de sus trabajadores y así todos los órganos de la sociedad contribuir al engrandecimiento de la Nación desde su propia función: el abogado procurando la justicia, el maestro educando, el periodista informando y el político administrando el tesoro público de la mejor manera. En esto consistía la utopía puesta en marcha por Masferrer: ${ }^{34}$

Masferrer, en su doctrina del Mínimum Vital, ha mostrado con otras palabras la trabazón de todos los hombres en un solo gran cuerpo. Ha dado a entender cómo, puesto que el mundo tiene una sola miseria total, al disminuir ésta, todos serán más felices. Disminuir el dolor de un solo pobre hará así más felices a los ricos.

El gran problema para Vargas Morán era que todos los políticos, independientemente de su ideología, cuando llegan al poder buscan su propio bienestar abusando de sus potestades y cuando los pueblos se los quieren quitar de encima, son objeto de represión, es por eso que decir fascismo, nacionalismo o marxismo son sólo distintos nombres de llamar a una misma esclavitud que se ha impuesto en la historia con distintas retóricas. Lo importante es entender que cuando un Estado no cumple con las necesidades del pueblo, éste se rebela y se levanta, produciéndose así el mar de sangre. Lo que el vitalismo pretende evitar, en definitiva, es la locura roja del choque violento y la muerte de hermano contra hermano y es por eso que Vargas Morán expresó: ¡Qué sacrificios hubiera ahorrado el Vitalismo en Rusia! ${ }^{35}$ Vargas Morán sigue en esta misma línea de ideas cuando asevera:

Pues bien: el Vitalismo no trata ni de evitar la inevitable transformación social, ni de acelerarla. Busca una fórmula de transición que haga inútil la convulsión sangrienta. Ya que no puede violarse una ley natural, puede servir su conocimiento para precaverse. Si nadie en el mundo puede suprimir el rayo, un Franklin endereza contra él un pararrayos, convirtiéndose en inofensivo. Y el Vitalismo es ahora -hay que comprenderlo bien- un pararrayos que anulará el desastroso efecto de la convulsión social. ${ }^{36}$

Como es evidente, Vargas Morán ve en la historia una evolución que en el campo social se reflejaría en un reformismo. Sostiene que del feudalismo al capitalismo hubo cierto avance, cierto progreso en cuanto al mejoramiento de las condiciones del trabajador y analiza que el gran problema del capitalismo es su poco interés en la implementación de políticas sociales que conlleven el

34. Mario Vargas Morán, "El liberalismo y la democracia III", Patria, sábado 22 de febrero de 1930, No. 549 , pág. 3 , año II.

35. Mario Vargas Morán, “El vitalismo y su función social”, Patria, jueves 26 de septiembre de 1929, págs. 1 y 4 , año II.

36. Ídem. 
bienestar de las masas, aunque está consciente de que este sistema no solo ha traído consigo efectos negativos sino también positivos, por ejemplo, la máquina liberó de cientos de trabajos penosos al hombre, las ciencias naturales avanzaron mucho y hubo un mejor aprovechamiento de los recursos naturales, -aunque hoy en día se le acuse de destruirlos- pero la debilidad de dicho sistema, como hemos dicho ya, radica en las injusticias que provoca y en ese sentido la Declaración de los Derechos del Hombre se vuelve un lirismo. Por lo tanto, desde la visión de Vargas Morán el sistema se debía readecuar o reajustar para evitar caer en radicalismos ideológicos como los del comunismo, sistema que intenta destruir el sistema, la moneda y la autoridad. ${ }^{37}$

Vargas Morán consideraba que el comunismo intentaba hacer un salto violento en la evolución natural del sistema y que mediante la revolución pretendía transformar de golpe todas las injusticias sociales e instituciones. Para él, los cambios más bien debían ser lentos y $\operatorname{trabajosos}^{38}$ y hacerse en base a derecho, respetando siempre la legalidad formal como en la sociedad romana que se tenía un contrato de compraventa mediante el cual se prevenían disputas posteriores entre comprador y vendedor, asegurándose además la igualdad de condiciones entre las partes. ${ }^{39}$

En síntesis, para este masferreriano donde regía la ley reinaba la paz, el orden social y la certeza de la propiedad individual, es decir, en toda sociedad donde se cumplían efectivamente los principios jurídico-morales que científicamente eran llamados "leyes" imperaba la cordialidad. Lo que Vargas Morán quiere decir es que los dirigentes romanos para evitar caer en la conflictividad de sus ciudadanos inventaron la ciencia del derecho que era la ciencia que establecía las causas y los efectos de los derechos y las obligaciones: ${ }^{40}$

La ciencia del Derecho no es ni puede ser el conocimiento de la ley positiva de cada país, como la ciencia de la física no consiste en el conocimiento de los anillos de Gravessande y del disco de Newton. Éstos y aquellas son simples aplicaciones prácticas de conocimientos abstractos. Y éstos y aquellas, solo sirven para el objeto que inspiró su creación, en tanto científicamente se ciñan a los principios científicos (...) imaginemos una ley que no responda al conocimiento perfecto del Derecho y que no se base en la observación directa del medio. Esa ley caerá forzosamente en desuso.

37. Mario Vargas Morán, “El Mínimum Vital y sus relaciones con el derecho II, Patria, domingo 10 de noviembre de 1929, No. 462, pág. 3, año II.

38. Ídem.

39. Mario Vargas Morán, "El vitalismo y sus relaciones con el derecho III", Patria, miércoles 13 de noviembre de 1929, No. 465, pág. 3, año II.

40. Ídem. 
Esto quiere decir que el Mínimum Vital saca a la luz los problemas sociales del medio, establece normas éticas o morales a seguir para solucionarlos y luego intenta que estas mismas normas se plasmen en leyes formales vigentes de carácter coercitivo. Es por eso, precisamente, que Masferrer quiso ser diputado. Además, quiere decir que el derecho no es una ciencia etérea aislada sino más bien un producto social, cuyo fin último es regir las distintas relaciones sociales de una cultura concreta. En esta vía, las leyes particulares de cada país se fundamentarían en ciertos principios doctrinarios de carácter universal como igualdad, justicia y solidaridad, las que irían más allá de los distintos cuerpos legales que rigen a cada nación. En otras palabras, el objetivo con el que nace el Mínimum Vital es ser una fuente doctrinal o filosófica a partir de la cual se creen leyes que defiendan la vida desde diferentes puntos de vista. La idea es que estas normas no solo se queden en buenas intenciones como señalan los teóricos marxistas sino que los códigos legales se apliquen de manera eficaz y eficiente, logrando transformaciones sociales concretas. ${ }^{41}$

Ahora bien, la crítica que Vargas Morán pasa por alto en este modelo y que con toda justicia podría ser señalado por el marxismo, es que este sistema jurídico generalmente responde a intereses creados. Las argollas de poder, comúnmente manipulan el sistema hasta controlarlo a su antojo. Marx, probablemente diría que el sistema de justicia capitalista nunca será justo en la medida que siempre responderá al poder político y económico de las elites del liberalismo. En este sentido, el análisis académico no puede ignorar los graves defectos del sistema que continuamente encontramos en la realidad social.

A pesar de este enorme defecto del Mínimum Vital, su espíritu es que predomine el imperio de la ley, lo que implicaría la supresión de la corrupción. Para poner un caso en concreto establece que a través de un sistema de recaudación público más eficiente y transparente se puede lograr la obtención de mayores ingresos para el Estado y éste disponer de mayores recursos para satisfacer las necesidades de sectores socialmente menos favorecidos, es decir, la riqueza del país se redistribuye de mejor manera siempre apegado a la ley en el supuesto de que el que gana más paga más. Otro caso sería crear leyes que protejan a los trabajadores respecto a la desventaja social y económica en la que se encuentran frente a su patrono sin la oportunidad que éste pueda doblarlas a su favor. ${ }^{42}$

Pero lo más importante en el Mínimum Vital es entender que antes de querer crear a diestra y siniestra leyes, primero se debe intentar cambiar la mentalidad de los ciudadanos, ya que las leyes por sí solas no cambian el alma colectiva de los pueblos, sino las ideas. Es mejor educar al hombre para que no consuma alcohol que decretar una ley prohibiendo su consumo. En este sentido, las ideas

41. Ídem

42. Ídem. 
tienen un mayor campo de acción que las leyes que actúan en un campo más restringido, o para explicarlo de otra forma, el derecho entra en acción cuando determinado hecho es proscrito o permitido en un determinado cuerpo legal, lo ético va más allá de lo legal y es por eso que ¿Qué sentido tendría crear leyes que combatieran el tráfico de drogas sino hubiera consumidores de droga? ¿O una ley que tratara de erradicar la trata de menores? ¿Si no existiera la prostitución? ${ }^{43}$

En realidad, para Vargas Morán los vicios son otra señal de enfermedad del organismo social, por ejemplo, el alcoholismo que tanto combatió Masferrer, desde su perspectiva, propiciaba la degeneración de la raza, ya que implicaba una intoxicación del cuerpo, similar a la que producen otros tipos de droga como el cigarro que contiene nicotina u otras que contienen heroína o morfina, o sea, distintas formas de veneno que conducen a sitios comunes: la enfermedad y la muerte. Lo curioso para el jurista era que a pesar de que había leyes vigentes en contra del consumo de alcohol y de que el Estado realizaba campañas antialcohólicas, el vicio no desaparecía y ni siquiera disminuía. El jurisconsulto, entonces, llega a la conclusión por sí mismo de que, a veces, las leyes positivas no se cumplen debido a intereses creados: ${ }^{44}$

Alguna razón oscura y poderosa debe existir en el fondo de todo ello para dejar estériles las propagandas moralizadoras y sin cumplir, todas las leyes orientadas a un mejoramiento moral colectivo. El sabor del tabaco es repugnante, la sensación producida por el alcohol es dolorosa, la reacción del organismo bajo el alcohol, agobiante. ¡Por qué pues, se emplean y se acostumbran a pesar de todo! ${ }^{45}$

Para Vargas Morán, entonces, no se debía atacar el vicio en sí mismo, sino a la causa oculta del mal, que efectivamente eran los intereses económicos de las empresas y la permisibilidad del Estado por los réditos que le reportaba dicha actividad en razón de los tributos a los cuales estaba sometida la bebida, pero además había que identificar a los consumidores de alcohol que, según él, eran los ricos ociosos que sólo vivían en el casino y los pobres que carecían de toda esperanza y que iban acumulando odio contra el medio que les rodeaba. Esto significaba que los vicios no respetan las clases sociales. ${ }^{46}$

En el campo social, lo primero era cambiar la conciencia de los explotadores antes que crear leyes que restringieran la actividad comercial. Ahora bien, Vargas Morán haciendo uso de sus conocimientos sobre la historia pensaba que ante el fracaso de la monarquía y de la democracia en el aspecto social-como

\footnotetext{
43. Ídem.

44. Mario Vargas Morán, “El vicio como síntoma”, Patria, viernes 13 de diciembre de 1929, №. 490, pág. 1, año Il:

45. Ídem.

46. Ídem.
} 
ya señalamos anteriormente-, surgieron grandes modelos totalitarios como el comunismo y el fascismo, los cuales se basaban en ser dictaduras dirigidas por una pequeña facción no elegida por nadie, pero que habían surgido necesariamente como el resultado de las circunstancias extremas del medio. Esto encuentra su razón de ser en que los modelos implementados hasta ese momento histórico no habían logrado satisfacer las necesidades vitales de los pueblos, entonces, a estos no les quedo otro camino que adherirse a posturas radicales: ${ }^{47}$

Todavía se da el caso que en ciudades atestadas de víveres perezcan por falta de alimento millares de personas humanas y, mientras gigantescas obras esperan, hay millones de trabajadores sin ocupación, que cruzan sus inútiles brazos en gesto desesperado de rencor contra todo y contra todos. Todos los fermentos de descomposición que notamos en la sociedad provienen de esa inacción forzada. Lógicamente, naturalmente, de cada uno de esos seres hambrientos para los cuales no tiene víveres la sociedad, son enemigos de ella. Son eternos rebeldes, que forman legión, y que por eso mismo son peligrosos.

Para Vargas Morán de no cambiarse estas condiciones era inminente la realización de la revolución y todos estos antecedentes históricos tenían que servir para hacer una reflexión sobre los distintos factores que la provocaban, siendo desde este ángulo, el Mínimum Vital la doctrina más adecuada para aplicarse como remedio en el proceso de adaptación del individuo a la sociedad:

El Mínimum Vital, como doctrina congruente y homogénea, aparece por primera vez en la historia del pensamiento humano; pero fragmentariamente había sido ya enunciada por diversos filósofos que no es el caso mencionar. Su fórmula es demasiado sencilla: predica el mejoramiento colectivo por el simple medio de asegurar absolutamente a todos, los medios indispensables para que puedan vivir, desarrollarse y funcionar normalmente. ${ }^{48}$

Para Vargas Morán, el vitalismo pretendía transformar a la sociedad por medio del convencimiento, pero a través de la ley positiva deseaba que sus postulados tuvieran una realización práctica y es aquí donde el Mínimum Vital entraba en íntima realización con los principios del derecho, en especial con dos, los cuales son: 1) "Todo individuo tiene derecho a buscar su bien y está obligado a no dañar a otro" y 2) "El bien social priva sobre el bien individual y, por tanto, la sociedad tiene derechos privativos y superiores al individuo". Este principio ya ha quedado explicado a través de la teoría del contrato social de Rousseau y se basa en que el derecho colectivo es más potente y de mayor jerarquía

47. Mario Vargas Morán, "El Mínimum Vital y sus relaciones con el derecho IV", Patria, domingo 17 de noviembre de 1929, No. 469, pág. 3, año II. 48. Ídem. 
al individual, pero esto no quiere decir, según Vargas Morán, que haya que destruirse la institución de la propiedad privada ${ }^{49}$ y de paso demuestra que la doctrina social de Masferrer no es filocomunista como muchos autores la han querido hacer parecer hasta el día de hoy:

De allí dimana la teoría de la propiedad privada, sean cualesquiera las declamaciones de los radicales que pretenden que la propiedad es un robo. La propiedad no lo es. La propiedad es la verdadera fuerza de cohesión, hasta hoy, que mantiene unidas las células del organismo social. Puesto que el hombre tiene derecho a buscar su bien, y su bien no es otro que la satisfacción de las necesidades propias, y entre esas necesidades se encuentra la sexual, debe la comunidad protegerle en ellas. La institución del matrimonio nace así, como la necesidad civil mucho antes que la ley positiva reconociera su existencia. ${ }^{50}$

Vargas Morán establece que el Mínimum Vital son todas aquellas necesidades instintivas que el hombre debe satisfacer en su carácter animal como proteger a sus hijos. El derecho, lo que viene a hacer, como un sistema normativo que la misma sociedad se da, es ayudar al individuo a cumplir con esa necesidad particular, por ejemplo, todo padre quiere que sus hijos una vez él haya fallecido no queden en el desamparo económico y que todos aquellos productos de su trabajo pasen a formar parte del patrimonio de aquellos familiares que más amó en vida, lo cual conduce al derecho de libre testamentifacción y transmisión de los bienes que tiene todo individuo como parte del denominado "Derecho Sucesorio". En este caso, la propiedad privada es un medio de protección y de felicidad del individuo y de la familia. Otra necesidad fundamental del ser humano es intercambiar productos y servicios para su propia supervivencia y como es indiscutible que el ser humano no puede vivir aislado nace el Derecho Mercantil para regular el comercio. ${ }^{51}$

Para Vargas Morán, ninguna ley positiva hasta ese momento había logrado traducir perfectamente los postulados científicos del derecho. La corrupción y los intereses creados, como hemos visto, muchas veces las volvían ineficaces. Además, no estaba conforme con la Escuela del Positivismo Jurídico ${ }^{52}$ que, según Hans Kelsen, es aquella que solo admite un saber del derecho cuyo objeto es el derecho positivo, o sea, todo aquel derecho creado mediante actos de voluntad del hombre mediante legislación o costumbre. Vargas Morán, más bien se adhiere a la llamada Escuela lusnaturalista que, según él, es aquella que reconoce que hay leyes anteriores y superiores a las leyes positivas. Kelsen a esta escuela la llama la "Metafísica del Derecho", ya que está identificada con la metafísica

\footnotetext{
49. Ibídem, pág. 7.

50. Ídem

51. Ídem

52. Mario Vargas Morán, "La doctrina del Mínimum Vital y sus relaciones con el derecho V", Patria, jueves 21 de noviembre de 1929, No. 471, pág. 3, año II.
} 
idealista de Platón en el sentido de que el mundo trascendente de las ideas se contrapone al mundo empírico, es decir, en el positivismo jurídico hay una separación entre lo que estrictamente se podría denominar derecho y moral. La idea principal del iusnaturalismo es que la persona tiene derechos aún antes de que estén consignados en cualquier ley escrita. ${ }^{53} \mathrm{Al}$ respecto Kelsen expresa:

La doctrina del derecho natural es -en contraposición al positivismo jurídico como doctrina "realista"- una doctrina jurídica idealista. Porque el derecho natural aceptado al lado del derecho real, el positivo, creado por el arbitrio humano y por lo tanto variable, es un derecho ideal, invariable, identificable con la "justicia". Pero la doctrina del derecho natural no es la doctrina idealista del derecho. Se distingue de otras doctrinas jurídicas idealistas -como lo indica su nombre-en que considera a la naturaleza como fuente de las normas del derecho ideal y justo. Esta naturaleza es la naturaleza en general, la totalidad de la realidad, o la naturaleza del hombre en especial. ${ }^{54}$

Vargas Morán sostiene que la ley positiva puede ser inadecuada o, incluso, injusta, pero la ley natural tal y como lo establece Kelsen siempre estará en concordancia con el ideal de justicia. ${ }^{55}$ En este sentido, habría que recordar que para Platón, el Estado era un organismo perfecto formado por individuos donde debía reinar la justicia, que consistía en la relación armónica entre las distintas partes de ese todo social. Para Platón, la ley debía ser verdadera y procurar el bien común. Esto es muy importante porque aquí ya hay una diferenciación entre ley natural y ley positiva. Platón ya hace una diferenciación entre la ley justa y la ley positiva. Siendo lo correcto que la primera debe convertirse en medida de la segunda y estar en constante retroalimentación: ${ }^{56}$

Así el verdadero derecho, la verdadera justicia, vive en el mundo de las ideas, y las leyes positivas no pueden pretender tener valor alguno sino en tanto participen de la idea de ley justa. Se podría decir que el Derecho Natural para Platón es un derecho ideal, sólo que por ser ideal no deja de ser real. Al contrario: es real. ${ }^{57}$

A causa de lo antes expuesto es que para Vargas Morán, el derecho debe ser siempre una ciencia experimental, es decir, utilizar el mismo método de "prueba y error" que utilizan las ciencias naturales. El objetivo debe ser crear

53. Hans Kelsen, "La doctrina del derecho natural y el positivismo jurídico", Revista sobre la enseñanza del derecho, año 6, No 12, 2008, págs. 183 y 184.

54. Ibídem, págs. 183 y 184.

55. Mario Vargas Morán, "La doctrina del Mínimum Vital y sus relaciones con el derecho V", Patria, jueves 21 de noviembre de 1929, No. 471, pág. 3, año II.

56. John Locke, Ensayo sobre el gobierno civil, Editorial Gradifco, $1^{\text {a }}$ Ed., Buenos Aires, Argentina, 2007, pág. 10.

57. Ídem. 
las leyes que más convengan a un pueblo según sus propias características y es por eso que el derecho es una ciencia esencialmente dinámica, ya que se debe transformar según se transformen las costumbres sin que esto signifique poner en riesgo la seguridad jurídica en un momento determinado. Ahora bien, Vargas Morán advierte que tampoco debemos caer en el irracionalismo jurídico de pensar de que porque una ley natural se introdujo en una ley positiva, la solución a tal problema está dada de forma automática, por ejemplo, no solo basta que una ley diga que se debe fomentar y respetar la identidad indígena, sino que es necesario que exista una institucionalidad que la haga cumplir. La ley vendría siendo como una facilitadora y garante en el juego de las costumbres. ${ }^{58}$

Habría que decir, entonces, que los derechos que consagra el Mínimum Vital y los que estatuye la ley natural son los que tiene toda persona por el simple hecho de nacer en una sociedad, los trae incorporados desde el mismo momento en que es persona, no tiene que luchar por adquirirlos, porque ya los posee intrínsecamente por el solo hecho de existir y son indispensables para el sostenimiento de la vida en general: alimentación, salud, vivienda, trabajo, propiedad. Si faltare alguno de ellos la vida del animal racional se pone en peligro, trae consigo un estado de grave precariedad que puede conducir a la muerte del hombre de una forma no natural, sino provocada por la dramática situación de injusticia social que impera en el medio. ${ }^{59}$ En base a esto Masferrer apuntó:

Por el simple hecho de ser traído a la existencia, un niño adquiere plenos derechos a la vida integra, y todas las fuerzas familiares y sociales deben subordinarse a la necesidad de procurarle esa vida integra. Sus padres, la Comuna, la Provincia, el Estado, han de constituir para él una cuádruple paternidad, a fin de que esa vida que se inicia adquiera su máxima potencialidad..."60

En este sentido, todos los coasociados están obligados a procurar los derechos de todos, tal como lo establece Rousseau. Nuestro derecho se vuelve la obligación del otro y viceversa y es por eso que la apatía es el mayor enemigo de la justicia social y es por eso que el Mínimum Vital cumple con una función concientizadora, pero al derecho positivo le corresponde hacer efectivas las obligaciones correlativas mediante una ley concreta, que entre más efectiva más ley es, es decir, una ley que no se aplica es inútil, es letra muerta. Para el vitalismo, las leyes deben tener un efecto práctico, deben evitar el acaparamiento de los medios de producción y la especulación comercial y es por eso que Vargas Morán afirmó: ${ }^{61}$

58. Mario Vargas Morán, "La doctrina del Mínimum Vital y sus relaciones con el derecho V", Patria, jueves 21 de noviembre de 1929, No. 471, pág. 3, año II.

59. Ídem.

60. Alberto Masferrer, El Mínimum Vital, Ensayos, CONCULTURA, $1^{\text {a }}$ Ed., San Salvador, El Salvador, 1996, pág. 67.

61. Mario Vargas Morán, "La doctrina del Mínimum Vital y sus relaciones con el derecho V”, Patria, 
Por eso satisface plenamente mi espíritu la doctrina del Mínimum Vital. Ella no pide a las leyes que mejoren el alma no propugna por una redención humana a base de decretos, no trata de arrancar el odio ancestral del corazón civilizado a base de un mandato de La Legislativa, sino que pide la aplicación de los principios sólidos, basados en la observación y observancia de las leyes naturales sin los cuales toda ley positiva flaquea por su base.

La fuerza del Mínimum Vital radica, entonces, en las reformas que trata de impulsar, es por eso que Masferrer hace de una forma muy elocuente la distinción entre beneficencia y derecho. Para él, no es que el Estado o la Sociedad le esté regalando nada al individuo, sino que su doctrina implica la restitución de aquellos derechos humanos fundamentales que, en un momento determinado, fueron violados por el mismo sistema, pero que ya se encontraban contenidos en los cuerpos legales de dicho sistema o que, simplemente, pertenecían al ámbito del derecho natural y que, en un momento dado, pueden ser introducidos al ámbito del derecho positivo, comenzando por la Constitución, por lo que surge la pregunta ¿Qué constitución civilizada en el mundo no ha incorporado a su texto el derecho natural a la vida? y en ese sentido Masferrer se transporta del ámbito de la moral o de la idea al ámbito de la justicia social como derecho primario y absoluto, que tendría que ser desarrollado mediante distintas leyes secundarias en cada país: ${ }^{62}$

Nosotros hacemos del derecho de todo hombre a un mínimum de vida integra, un Derecho Absoluto; y del deber de la colectividad de procurarle a todo hombre un mínimum de vida integra, hacemos un Deber Absoluto.

Para ir concluyendo, lo que Vargas Morán trató de explicar a través de su conferencia es que el hombre tiene una esencia naturalmente egoísta y que en el transcurso de la historia ha habido varios sistemas o modelos sociales que han intentado armonizar este espíritu individualista con la vida colectiva, pero hasta ese momento ninguno había podido lograr que esa relación fuera perfecta, ni siquiera el marxismo que en algunas ocasiones, a la hora de aplicarse de forma real en las sociedades, había logrado exactamente lo contrario, es decir, la supresión de la vida. En esa dirección, el Mínimum Vital era, según él, la mejor fórmula para lograr el tan anhelado bien común. ${ }^{63}$

Para corroborar esto habría que señalar que en el periódico Patria se publicó un discurso del Secretario de Instrucción Pública de México de esa época, el cual

jueves 21 de noviembre de 1929, No. 471, pág. 3, año II.

62. Alberto Masferrer, "El mínimum vital”, Ensayos, CONCULTURA, 1ª Ed., San Salvador, El Salvador, 1996, pág. 75.

63. Mario Vargas Morán, "La doctrina del Mínimum Vital y sus relaciones con el derecho V”, Patria, jueves 21 de noviembre de 1929, No. 471, pág. 3, año II. 
tenía por objetivo desarrollar los derechos del niño, sector al cual Masferrer consideraba como uno de los más vulnerables dentro de la sociedad. El niño tenía derecho a: 1) que se les garantizara la vida como bien supremo y a ser protegido contra la pobreza y el abandono, 2) a asearse y vestirse de manera adecuada, a una buena alimentación y a agua potable para su buen desarrollo, 3) al juego y a la recreación sanas, 4) a la salud, a la educación y al recto criterio moral en base a principios como la solidaridad, 5) a promover sus virtudes, destrezas e intereses, 6) a tener un círculo más o menos extenso de relaciones sociales y amistades y 7) a una escuela donde pudiera adquirir sus conocimientos. ${ }^{64}$

Ahora bien, en el transcurso de este artículo se ha establecido que el Mínimum Vital es una doctrina que intenta proteger y fomentar la vida, ahora bien habría que cerrar el mismo abordando un hecho que también toma en cuenta, y es que la muerte también forma parte de la vida, es por eso que Alberto Guerra Trigueros escribió el artículo "El derecho a morir, hacia un Mínimum Vital para los muertos”, cuyo título a primera vista podría resultar contradictorio, pero que se refiere a que la muerte es un suceso inevitable y por tanto, todas las personas deben gozar de su derecho a bien morir, el cual implica un terreno de tierra en un cementerio digno. Guerra Trigueros afirma que lo primero que hay que resaltar en este sentido es el alto costo del derecho de nicho, el cual una persona pobre promedio o su familia no puede pagar: ${ }^{65}$

La sociedad tiene un sencillo lema que aplica a esta materia: "El que quiera celeste que le cueste", dice la sociedad. El que quiera darse el lujo de morir, que trabaje; que sude y se afane hasta reunir el peculio necesario para costear los funerales, para pagar un pedazo de terreno que ni siquiera se puede sembrar de maíz. ¡Como si el derecho a morir no lo hubiéramos adquirido todos por igual y en el momento mismo de nacer, como si por igual no lo hubieran pagado nuestras madres con su sangre!

Ante este problema, Guerra Trigueros, estableció que había que limitar el deseo de ganancia de las empresas comerciales de servicios fúnebres y de las compañías de seguro de vida e intentar instaurar un sistema de Estado Social del Porvenir que comprendiera nacimientos y muertes. Dentro del primer aspecto todas las mujeres tendrían derecho a dar a luz en condiciones iguales y el Estado debía reconocer la importancia de la función social de la maternidad fundando guarderías, garantizando su acceso, principalmente, a las mujeres de escasos recursos económicos o bien atenderlas en su domicilio. El Estado en este sentido, tendría que demarcar una asignación especial dentro del presupuesto general y quedar establecido mediante legislación. Sobre el segundo aspecto aseveró: ${ }^{66}$

64. "Los derechos supremos", Patria, martes 25 de junio de 1929, No. 346, págs. 1 y 5, año II. 65. Alberto Guerra Trigueros, "El derecho a morir, hacia un Mínimum Vital para los muertos", Patria, sábado 27 de abril de 1929, №. 297, pág. 1, año I.

66. Ibídem, pág. 5 . 
Por otra parte, todos los hombres tenemos derecho a una tumba: esa tierra por lo menos, debe ser de todos, siquiera sea para abonarla con nuestros huesos. Y aquí también, aquí sobre todo, es donde debe intervenir el Estado, tomando todos los entierros a su cargo: porque también los muertos deben tener su... Mínimum Vital. El Estado tiene el deber de proclamar públicamente que y en todos los tonos y hasta por medio de carteles anunciadores, que siempre y en cualquier tiempo es lícito morirse, como y cuando le venga a uno en gana, sin trabas ni formalidades, y aun careciendo en absoluto de recursos, porque éstos los suplirá el Estado.

En conclusión, con el presente análisis queda claro que el Mínimum Vital cubre toda la gama de derechos que el ser humano posee por el solo hecho de existir. Éstos deben ser garantizados primordialmente por el Estado dentro de un sistema económico justo. Habría que señalar también que, aunque es una doctrina que, -tal y como se ha hecho en el transcurso de este ensayo- puede analizarse a la luz de grandes filósofos del derecho como Rawls, Rousseau y Kelsen, su objetivo fundamental y último no es ése, sino promulgar todos estos derechos que nunca, nunca deben quedarse encerrados en complejas discusiones teóricas que a lo sumo, podrían interesarle a estudiosos y profesores de la filosofía, del derecho o de la política, ya que es una teoría hecha y dirigida hacia la vida. Con esto se hace referencia a las graves limitaciones y problemas con los que miles de salvadoreños de carne y hueso tienen que enfrentarse a diario.

\section{Bibliografía}

\section{Libros primarios}

Comte, Augusto, Discurso sobre el espíritu positivo. Digitalizado por Dot-com. Disponible en http://www.libro.dot.com

Locke, John, Ensayo sobre el gobierno civil. Buenos Aires, Argentina: Editorial Gradifco, $1^{\text {a Ed., }} 2007$.

Masferrer, Alberto, “Maquinas y hombres”, Obras escogidas, tomo II, Editorial Universitaria de El Salvador, $1^{\text {a }}$ Ed. San Salvador, 1971.

Masferrer, Alberto, El Mínimum Vital, Ensayos, San Salvador: CONCULTURA, $1^{\text {a }}$ Ed., 1996. Platón, La República, Editorial Gradifco. Buenos Aires, 2007.

Rousseau, Jean-Jacques, El contrato social, Editorial Biblioteca Nueva. Madrid, 2003.

\section{Libros secundarios}

Alamanni de Carrillo, Beatrice. Justicia, derecho y ley, Editorial UCA, $1^{\text {a }}$ Ed. San Salvador, 2009. 


\section{Artículos de periódicos}

Guerra Trigueros, Alberto, "El derecho a morir, hacia un Mínimum Vital para los muertos", Patria, sábado 27 de abril de 1929, No. 297, págs. 1 y 5, año I.

Vargas Morán, Mario, “El vitalismo y sus relaciones con el derecho I”, Patria, viernes 8 de noviembre de 1929, No. 460, pág. 3, año II.

Vargas Morán, Mario, “El Mínimum Vital y sus relaciones con el derecho II”, Patria, domingo 10 de noviembre de 1929, No. 462, pág. 3, año II.

Vargas Morán, Mario, “El vitalismo y sus relaciones con el derecho III”, Patria, miércoles 13 de noviembre de 1929, No. 465, pág. 3, año II.

Vargas Morán, Mario, “El Mínimum Vital y sus relaciones con el derecho IV”, Patria, domingo 17 de noviembre de 1929, No. 469, pág. 3, año II.

Vargas Morán, Mario, "La doctrina del Mínimum Vital y sus relaciones con el derecho V", Patria, jueves 21 de noviembre de 1929, No. 471, pág. 3, año II.

Vargas Morán, Mario, "El liberalismo y la democracia I", Patria, jueves 20 de febrero de 1930, No. 547, págs. 3 y 6, año II.

Vargas Morán, Mario, “El liberalismo y la democracia II”, Patria, viernes 21 de febrero de 1930, No. 548, pág. 3, año II.

Vargas Morán, Mario, “El liberalismo y la democracia III”, Patria, sábado 22 de febrero de 1930, No. 549, pág. 3, año II.

Vargas Morán, Mario, “El vitalismo y su función social”, Patria, jueves 26 de septiembre de 1929, pág. 1 , año II.

Vargas Morán, Mario, "El vicio como síntoma”, Patria, viernes 13 de diciembre de 1929, No. 490, pág. 1, año II.

Los diez mandamientos de la justicia social”, Patria, viernes 7 de junio de 1929, No. pág. 3, año I.

“Los derechos supremos”, Patria, martes 25 de junio de 1929, No. 346, págs. 1 y 5, año II.

\section{Artículos de revistas académicas}

Caballero, José Francisco, La teoría de la justicia de John Rawls, Voces y contextos, No. 2, año I, 2006, pp. 1-22.

Echeverry Enciso, Yesid y otro, El concepto de justicia en John Rawls, Revista Científica Guillermo de Ockham, volumen 4, No. 2, julio-diciembre 2006, Colombia, pp. 27-52.

Kelsen, Hans, La doctrina del derecho natural y el positivismo jurídico, Revista sobre la enseñanza del derecho, año 6, No. 12, 2008, pp. 183-198.

Murillo Torrecilla, F. Javier y otro, Hacia un concepto de justicia social, REICE, Revista Iberoamericana sobre calidad, eficacia y cambio en educación, Vol. 9, No. 4, 2011, pp. 8-23.

\section{Artículos de internet}

Fuentes Oliva, Regina, “Crítica: el vitalismo de Masferrer”, disponible en: www.caratula. net/ediciones/44/critica-rfuentes.php 